\title{
Correction to: MicroRNA-224 sustains Wnt/ $\beta$-catenin signaling and promotes aggressive phenotype of colorectal cancer
}

Tingting Li $\mathrm{Li}^{1,2,3 \dagger}$, Qiuhua Lai ${ }^{1,2,3 \dagger}$, Shuyang Wang ${ }^{1,2,3}$, Juanjuan Cai ${ }^{1,2,3}$, Zhiyuan Xiao ${ }^{1,2,3}$, Danling Deng ${ }^{1,2,3}$, Liuqing He $\mathrm{H}^{1,2,3}$, Hongli Jiao ${ }^{1,2,3}$, Yaping Ye $\mathrm{e}^{1,2,3}$, Li Liang ${ }^{1,2,3}$, Yanqing Ding ${ }^{1,2,3}$ and Wenting Liao ${ }^{1,2,3^{*}}$

\section{Correction to: J Exp Clin Cancer Res 35, 21 (2016) \\ https://doi.org/10.1186/s13046-016-0287-1}

Following publication of the original article [1], the authors identified minor errors in image-typesetting in Figs. 3 and 4; specifically:

3C: miR-224/GSK3B/SFRP2 group (top and bottom right panel)

4A: figure adjusted to show only areas of the body containing the tumour

4C: H\&E staining in the NC group (top left)

The corrected figures are given below. The corrections do not have any effect on the results or conclusions of the paper. The original article has been corrected.

\footnotetext{
The original article can be found online at https://doi.org/10.1186/s13046016-0287-1.

* Correspondence: liaowt2002@gmail.com

${ }^{+}$Tingting Li and Qiuhua Lai contributed equally to this work.

'Department of Pathology, Nanfang Hospital, Southern Medical University, Guangzhou 510515, Guangdong, China

${ }^{2}$ Department of Pathology, School of Basic Medical Sciences, Southern Medical University, Guangzhou, Guangdong, China

Full list of author information is available at the end of the article
}

(c) The Author(s). 2021 Open Access This article is licensed under a Creative Commons Attribution 4.0 International License, which permits use, sharing, adaptation, distribution and reproduction in any medium or format, as long as you give appropriate credit to the original author(s) and the source, provide a link to the Creative Commons licence, and indicate if changes were made. The images or other third party material in this article are included in the article's Creative Commons licence, unless indicated otherwise in a credit line to the material. If material is not included in the article's Creative Commons licence and your intended use is not permitted by statutory regulation or exceeds the permitted use, you will need to obtain permission directly from the copyright holder. To view a copy of this licence, visit http://creativecommons.org/licenses/by/4.0/ The Creative Commons Public Domain Dedication waiver (http://creativecommons.org/publicdomain/zero/1.0/) applies to the data made available in this article, unless otherwise stated in a credit line to the data. 


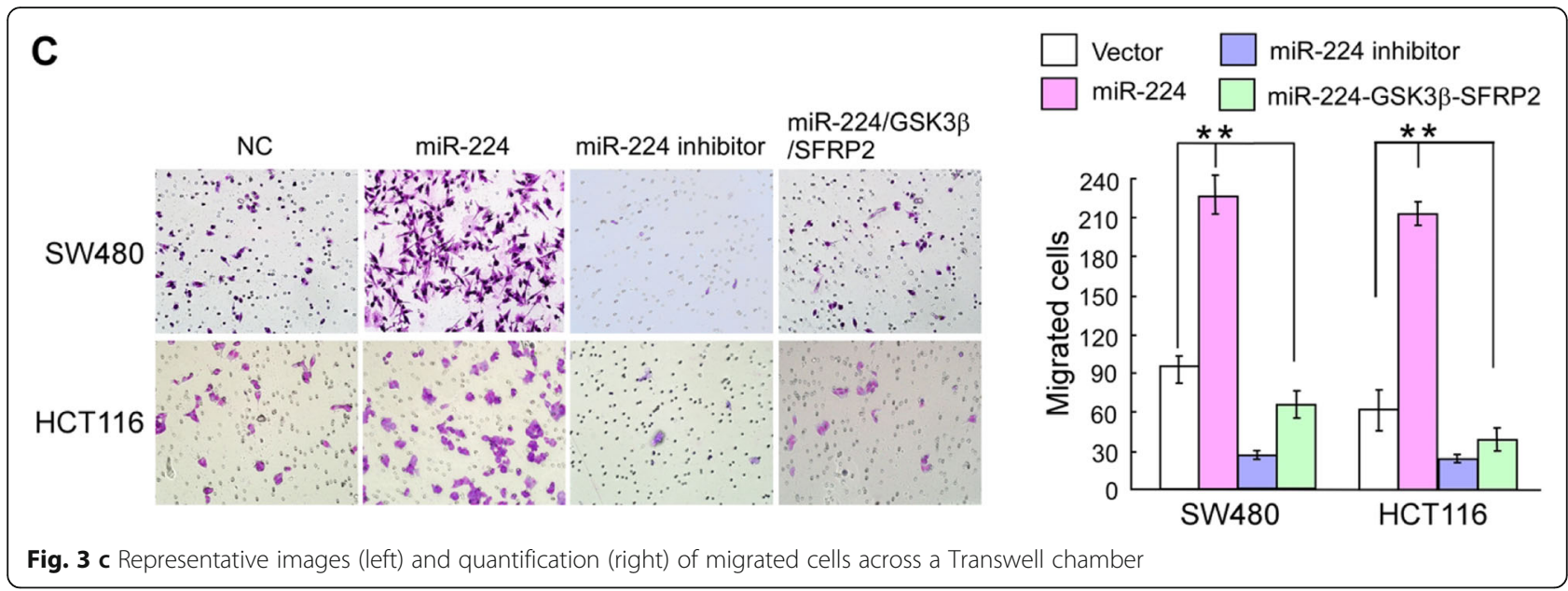

\section{A}

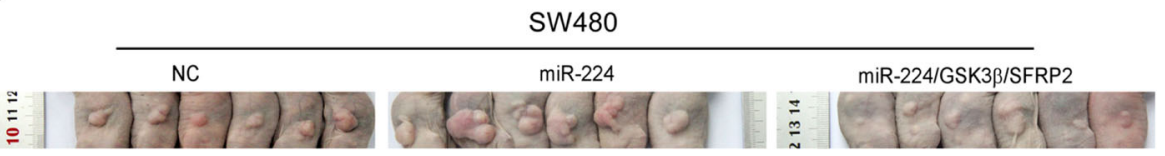

B

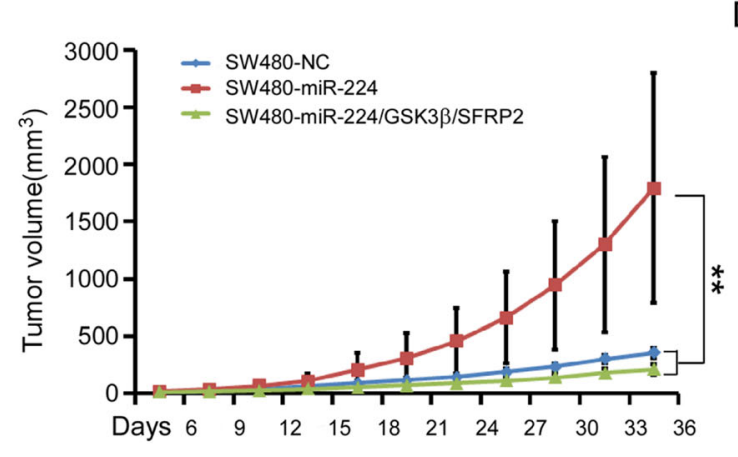

D $\square$ NC

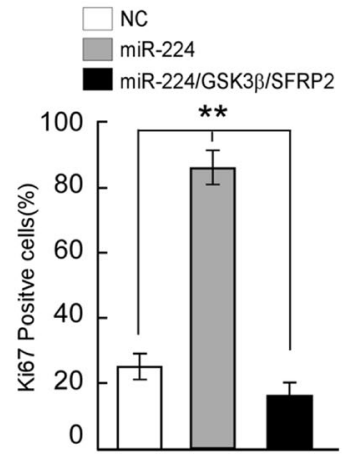

C

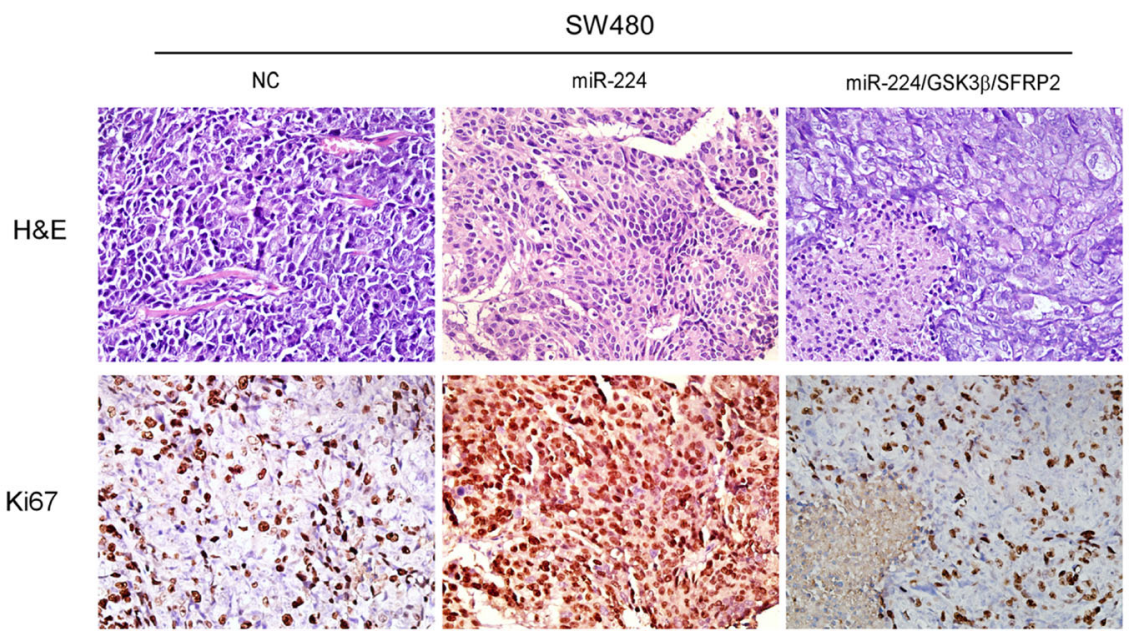

Fig. 4 GSK3 3 and SFRP2 are the bona fide effector of miR-224 in vivo. a Tumor xenograft model. Cells were injected into the hindlimbs of nude mice $(n=6)$. Representative images of the tumors are shown. $\mathbf{b}$ Tumor volumes were measured on the indicated days. Data points are presented as the mean tumor volume \pm SD. $\mathbf{c}$ Histopathology of xenograft tumors. The tumor sections were under H\&E staining and $\mathrm{HC}$ staining using antibody against Ki-67. $\mathbf{d}$ The percentage of Ki67 positive cells. Error bars represent mean \pm SD from 3 independent experiments; ${ }^{*} p<0.05,{ }^{* *} p<0.01$ 


\section{Author details}

'Department of Pathology, Nanfang Hospital, Southern Medical University, Guangzhou 510515, Guangdong, China. ${ }^{2}$ Department of Pathology, School of Basic Medical Sciences, Southern Medical University, Guangzhou,

Guangdong, China. ${ }^{3}$ State Key Laboratory of Oncology in Southern China, Department of Experimental, Guangzhou, Guangdong, China.

Published online: 27 April 2021

\section{Reference}

1. Li T, Lai $Q$, Wang $S$, et al. MicroRNA-224 sustains Wnt/B-catenin signaling and promotes aggressive phenotype of colorectal cancer. J Exp Clin Cancer Res. 2016;35:21. https://doi.org/10.1186/s13046-016-0287-1. 